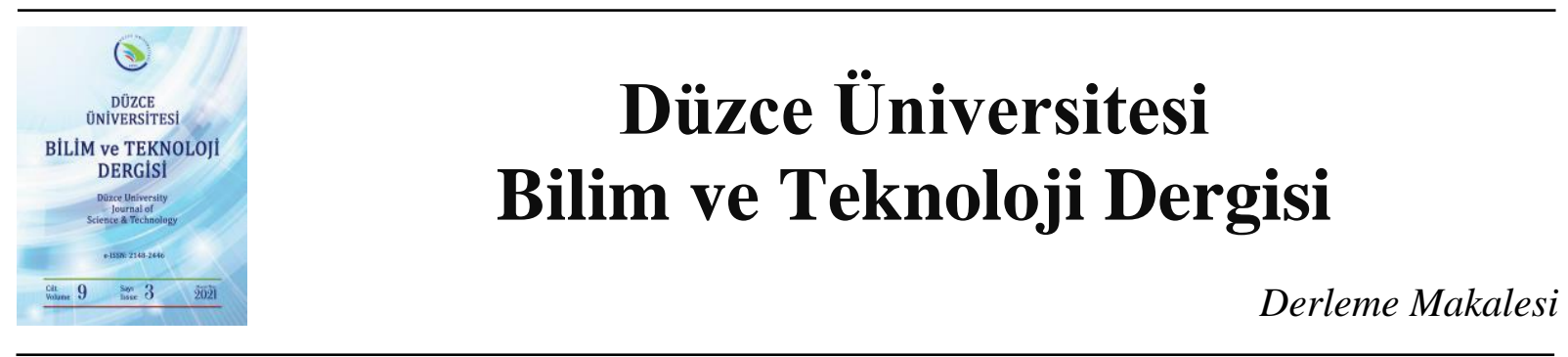

\title{
Perovskit Güneş Pilleri ve Kararsızlık Problemleri Üzerine Bir Araştırma
}

\author{
Cevahir TARHAN ${ }^{\mathrm{a}}$, (D) Berces KURT ${ }^{\mathrm{b}, *}$ \\ ${ }^{a}$ Uçak Gövde-Motor Bölümü, Havacılık ve Uzay Bilimleri Fakültesi, Erciyes Üniversitesi, Kayseri, TÜRKIYYE \\ ${ }^{b}$ Sivil Havacılık Anabilim Dalı, Fen Bilimleri Enstitüsü, Erciyes Üniversitesi, Kayseri, TÜRKIYYE \\ * Sorumlu yazarın e-posta adresi: brcs_krt@hotmail.com
}

\begin{abstract}
ÖZET
Günümüzde yaygın olarak kullanılan yenilenemeyen enerji kaynaklarının (kömür, doğalgaz, petrol vb.) çevre üzerinde zararlı etkileri bulunmaktadır. Ayrıca bu tür kaynaklar kullanıldıkça tükenme sorunuyla karşılaşmaktadırlar. Dünyanın enerji ihtiyacını, doğaya zarar vermeden ve sürdürülebilir bir formda üretebilmek için yenilenemeyen enerji kaynakları yerine yenilenebilir enerji kaynaklarının kullanımı yaygınlaştırılmalıdır. Potansiyeli en yüksek olan yenilenebilir enerji kaynağı güneştir. Bu bağlamda güneşten enerji elde edebilmek için de güneş pilleri kullanılmaktadır. Literatürde güneş enerjisinden enerji elde edebilmek için çoğunlukla silisyum bazlı güneş pillerinin kullanıldığı belirtilmektedir. Ama bu silisyum bazlı güneş pillerinin üretimi oldukça zor ve maliyetlidir. Bu güneş pillerinin olumsuzluklarını ortadan kaldırmak için literatürde güneş pilleri üzerine çalışmaların yapıldığı görülmektedir. Bu bağlamda organik güneş pillerinden biri olan perovskit güneş pilleri üzerinde birçok araştırma yapılmıştır. Perovskit güneş pillerinin verimi, ilk üretimlerinden sonraki on yıl içinde diğer güneş pilleri ile rekabet edebilecek seviyeye çıkmıştır. Ayrıca bu güneş pillerinin maliyeti de oldukça düşüktür. Ancak perovskit güneş pilleri üretildikten sonra su buharı, oksijen, elektriksel alan, ışı ve sıcaklık gibi faktörlerden kaynaklanan bozunmalar ile karşılaşmaktadırlar. Bu makalede, güneş enerjisi ve güneş pilleri ile ilgili literatürdeki makalelerin derlemesi ve değerlendirilmesi yapılmıştır.
\end{abstract}

Anahtar Kelimeler: Güneş enerjisi; Perovskit güneş pilleri; Güneş pillerindeki kararsızllk; Güneş pili veriminin iyileştirilmesi

\section{A Review on Perovskite Solar Cells and Their Instability Problems}

\begin{abstract}
Non-renewable energy resources (coal, natural gas, petroleum, etc.), which are widely used today, are harmful for the environment. In addition, as such resources are used, they encounter the problem of depletion. The use of renewable energy sources instead of non-renewable energy resources should be made widespread in order to produce the energy need of the world in a sustainable form without harming the nature. The most potential renewable energy source is the sun. In this context, solar cells are used to obtain energy from the sun. It is stated in the literature that mostly silicon-based solar cells are used to obtain energy from solar energy. But these silicon-based solar cells are very difficult and costly to produce. Therefore new solar cell technolgies and materials have been introduced in the literature. In this context, many studies have been done on perovskite solar cells, which are one of the organic solar cell types. The efficiency of perovskite solar cells has reached a level that can compete with other solar cells very soon after their first production. In addition, the cost of these solar cells is very low. However, after perovskite solar cells are produced, they encounter instability problems. In this article, the articles in the literature on solar energy and solar cells have been compiled and evaluated.
\end{abstract}

Keywords: Solar energy; Perovskite solar cell; Instability in solar cells; Solar cell efficiency improvement

Geliş: 06/12/2020, Düzeltme: 11/03/2021, Kabul: 17/03/2021 


\section{GIRIS}

Taş kömürü, linyit, petrol, doğal gaz, toryum gibi çevre dostu olmayan geleneksel enerji kaynakları kullanımı oldukça maliyetlidir. Ayrıca bu enerji kaynakları doğada sınırlı miktarda bulunmaktadır. $\mathrm{Bu}$ etkenlerden dolayı dünya genelinde geleneksel enerji kaynaklarının kullanımı azalmaktadır $[1,2]$. Bu tür doğal kaynakların kullanılmasıyla, çevreye zararlı gazların salınımı, küresel 1sınma, ozon tabakasının incelmesi gibi çevresel problemler de meydana gelmektedir [3]. Bundan dolayı, bu tür kaynakların yerine rüzgâr enerjisi, biyokütle enerjisi, hidrojen enerjisi, güneş enerjisi gibi yenilenebilir enerji kaynakları kullanılmalıdır. Özdemir ve Günduğar [4] çalışmalarında, yenilebilir enerji kaynaklarının düşük maliyetli olduğunu ve çevreye zararlı olmadıklarını belirtmişlerdir. Zhang ve ark. [5] çalışmalarında güneş enerjisinin en etkili yenilenebilir enerji kaynağı olduğunu belirtmişlerdir. Rüzgâr türbinleri, hidroelektrik, güneş pilleri, biyokütle kaynaklı sıv1 yakıtlar, biyokütle ateşlemeli elektrik üretimi gibi tüm yenilenebilir enerji teknolojileri arasında güneş enerjisini kullanan fotovoltaik teknolojisi en umut verici olanı olarak kabul edilmektedir. Çünkü dünyadaki tüm yaşam, alglerin fotosentezinden sonra güneş enerjisine dayanmaktadır [6,7]. Güneşten dünyaya gelen yıllık enerji toplamı 1.5 katrilyon $\left(1.5 \times 10^{15}\right) \mathrm{MW} / \mathrm{sa}$ 'tir. Bu enerji miktarı, dünyada insanların 1 yılda tükettiği enerjinin tam 28.000 katına eşdeğerdir [8]. Fotovoltaik teknolojideki ilerlemeler göz önüne alındığında, güneş pillerinin verimliliğini ve elektrik enerjisi üretimini iyileştirme çabalarının devam ettiği görülmektedir. Bilgin ve Çelebi [9], çalışmalarında, iki yönlü güneş takip sistemi ile \%41,34 daha fazla elektrik enerjisi üretimi elde edilebileceğini belirtmişlerdir. Güneş enerjisinden faydalanabilmek için radyasyonunu doğrudan elektriğe dönüştüren güneş pilleri kullanılmaktadır. Güneş pilleri, uydu sistemleri, kol saatleri, güneş firınları, bahçe aydınlatması, hesap makineleri gibi alanlarda, kullanılabilmektedir [10]. Kafle ve ark. [11] çalışmalarında, perovskit güneş pillerinin, güneş enerjisini elektrik enerjisine dönüştüren çevre dostu bir yöntem olduğunu belirtmişlerdir. Jena ve ark. [12] çalışmalarında, perovskit güneş pilleri teknolojisinde büyük ilerlemeler kaydedildiğini belirtmişlerdir. Ayrıca bu güneş pilleri oldukça kolay tekniklerle üretilebilmektedir ve aynı zamanda, esnek alt tabakalara uyum sağlayabilirler [13]. Bu güneş pillerindeki verim oranının artması, ticarileştirmeye yönelik maliyet avantajlarını artıracaktır [14]. Perovskit güneş pilleri, adını yapılarında aktif katman olarak kullanılan perovskit minerali $\left(\mathrm{CH}_{3} \mathrm{NH}_{3} \mathrm{XY}_{3}\right)$ şeklinde kristalleşen malzemeden almaktadır [15]. Hibrit malzemelerden olan $\mathrm{CH}_{3} \mathrm{NH}_{3} \mathrm{PbX}_{3}(\mathrm{X}=\mathrm{Cl}, \mathrm{Br}, \mathrm{I})$, (metil-amonyum kurşun iyodür klorür) incelendiğinde çok ilginç optik ve elektriksel özellikleri olduğu görülmektedir. Bunlar arasında, güneş spektrumundan gelen foton sayısının en yoğun olduğu yere karşılık gelen 1.39 $\mathrm{eV}$ bölgesinde bir direkt bant aralığına sahip oluşları, elektronlar için $7.5 \mathrm{~cm}^{2} \mathrm{~V}^{-1} \mathrm{~s}^{-1}$, delikler (holes) için $12.5-66 \mathrm{~cm}^{2} \mathrm{~V}^{-1} \mathrm{~s}^{-1}$ gibi yüksek taşıyıcı mobilitesine sahip olmaları, $100 \mathrm{~nm}-1000 \mathrm{~nm}$ aralığında yüksek taşıyıcı difüzyon uzunluklarına sahip olmaları, yüksek soğurma katsayısına sahip olmaları, çözelti bazlı üretilebilmeleri gibi özellikleri güneş pili uygulamaları için çok elverişlidir [16]. Ayrıca bu güneş pillerinin düşük maliyetli olması, üretiminin kolay olması ve veriminin yüksek olması gibi avantajları da bulunmaktadır [17]. Wu ve ark. [18] çalışmalarında, perovskit tipi güneş pillerinin veriminin son on y1l içinde \%3,8'den \%25,2'e yükseldiğini belirtmişlerdir. Akyürekli ve ark. [19] çalışmalarında perovskit güneş hücrelerinin çok hızlı güneş enerjisi çevrim verimine sahip olduğunu belirtmişlerdir. Perovskit güneş pilleri son yıllarda, yüksek 1şık emici özelliği sayesinde büyük ilgi görmektedir [20,21]. Li ve ark. [22] çalışmalarında, günümüzde \%25,2 güç dönüştürme verimliliğine sahip olan perovskit güneş hücrelerinin, 2020 yılında 'National Renewable Energy Laboratory' tarafindan onaylandığını belirtmişlerdir. Son yıllarda silikon bazlı güneş pillerinin maliyeti oldukça azalmıştır ve bu güneş pillerinde foto-dönüşüm verimliliği artmıştır. Silikon güneş pillerinin verimliliği, teorik olarak tahmin edilen \%29,4 (Shockley-Quisser limiti) değerine çok yakın bir şekilde \%26,6'ya ulaştı [23]. Ayrıca silikon güneş pillerinin kalınlığının 2029 yılına kadar $100 \mu$ m'ye kadar inceltilmesi beklenmektedir [24]. Ama bu silikon bazlı güneş pillerinin, sert hazırlık koşulları ve ciddi çevre kirliliği gibi dezavantajları vardır. Perovskit güneş pilleri ile silikon güneş pillerinin verimleriyle ilgili karşılaştırmaları 'Şekil 1'de görülmektedir [17,25]. 


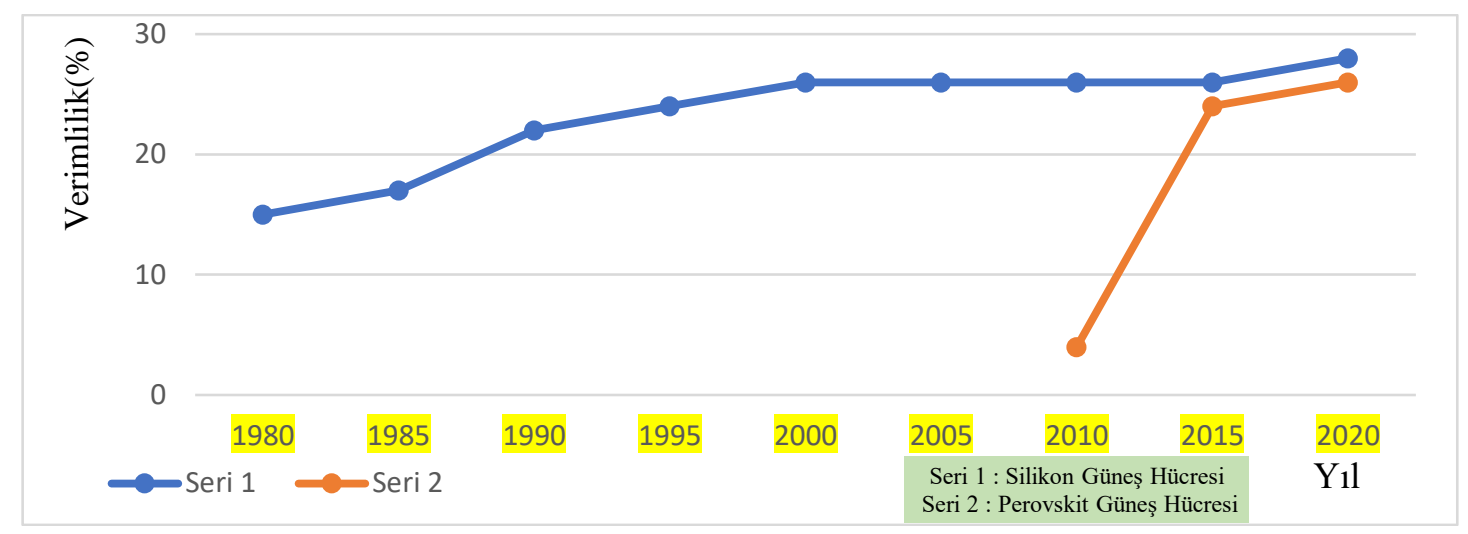

Şekil 1. Perovskite güneş pilleri ile silikon güneş pillerinin verimliliğinin karşılaştırılması [17,25].

Şekil 1'e bakıldığında silikon güneş pillerinin 1980 ve perovskit güneş pillerinin de 2010 yılında üretilmeye başlandığ görülmektedir. Perovskit ve silikon güneş pillerinin verimlilik değerlerine baktığımızda, perovskit güneş hücrelerinin veriminde daha hızlı artış olduğunu görmekteyiz.

Kojima ve ark. [26] 2009 yılında ilk perovskit güneş hücresi deneyini yapmışlardır. Bu çalışmada, $\mathrm{CH}_{3} \mathrm{NH}_{3} \mathrm{PbX}_{3}(\mathrm{X}=\mathrm{Br}, \mathrm{I})$ yapısındaki perovskit güneş hücresinde $\mathrm{X}$ yerine $\mathrm{Brom}(\mathrm{X}=\mathrm{Br})$ kullanıldığında $\% 3,1, X$ yerine Iyot $(X=I)$ kullanıldığında ise $\% 3,8$ verimlilik değerine ulaşılmıştır. $\mathrm{Bu}$ ilk denemeden yaklaşı 2 yıl sonra, 2-3 nm ebatlarındaki \%6,5 verime sahip kuantum nokta duyarlı güneş pili $\left(\mathrm{CH}_{3} \mathrm{NH}_{3} \mathrm{PbI}_{3}\right)$ üretilmiştir [27]. Green ve ark. [28] çalışmalarında, iyi performanslı perovskit güneş hücrelerinin 2012 yılında üretilmeye başlandığını belirtmişlerdir. Üretilmeye başlanmasından kısa bir süre sonra da bu alanda büyük gelişmeler kaydedildiğini belirtmişlerdir. $\mathrm{Bu}$ alanda yapılan çalışmalar sayesinde bu güneş hücrelerinin verimlilik değeri \%22,1'e ulaşmıştır [2931]. Li ve ark. [22] ise çalışmalarında, 2020 y1lında perovskit güneş pillerinin $\% 25,2$ güç dönüştürme verimlilik değerine ulaştığını belirtmişlerdir. Perovskit güneş pilleri, diğer güneş pillerine göre yüksek emilim katsayısına $\left(10^{5} \mathrm{~cm}^{-1}\right.$ den büyük) sahiptir. $\mathrm{Bu}$ güneş pillerin işlenebilmeleri için yüksek sıcaklığa gerek yoktur. Ayrıca perovskit güneş pilleri, sentetik fizibilite, yavaş yük taşıyıcı rekombinasyon oranı, üretim kolaylığı, kolay yük taşıyıcı ayrımı gibi avantajlara sahiptir. Bu avantajlar sayesinde perovskit güneş pilleri, bakır indiyum galyum diselenid (CIGS), kadmiyum tellür (CdTe) ve kristal silikon güneş pillerinden daha fazla tercih edilmektedirler [32]. Zhang ve Park [33] çalışmalarında, ince kalınlıkta (200 nm'den küçük) perovskit güneş hücrelerinin üretilebileceğini ve bu sayede daha yüksek verim değeri elde edilebileceğini belirtmişlerdir. Wali ve ark. [34] çalışmalarında belirttikleri gibi perovskit güneş hücrelerinin katmanlı yapısı 'Şekil 2'de görülmektedir. 'Şekil 2'ye bakıldığında, elektron bloke edici katmanı olarak $\mathrm{TiO}_{2}$ katmanı, delik taşıma katmanı (HTL) olarak Spiro-OMeTAD, FTO/glass yüzeyi, $\mathrm{CH}_{3} \mathrm{NH}_{3} \mathrm{PbI}_{3}$ perovskit katmanı ve $\mathrm{Au}$ elektrot yapıları görülebilmektedir. $\mathrm{TiO}_{2}$ katmanı ve Spiro-OMeTAD katmanı, perovskit güneş hücrelerinin verimliliği arttırmaktadır. Ayrıca $\mathrm{TiO}_{2}$, şeffaf yapıda olduğu için ve geniş bant aralığına sahip olduğu için güneş pillerinde sıklıkla tercih edilmektedir. $\mathrm{TiO}_{2}$ katmanı, perovskit güneş hücrelerindeki emici tabakanın büyümesini sağlamak için kullanılmaktadır. Delik taşıma katmanının (HTL) ara yüzündeki iyon birikimi, delik ekstraksiyonlarını engellemektedir. En yaygın kullanılan delik taşıma katmanı (HTL) olan 2,2',7,7'-tetrakis ( $N, N$-di-p-methoxyphenyl-amine)-9, $9^{\prime}$ spirobifluorene (spiro-OMeTAD) yüksek cihaz performansına sahiptir [35-37].

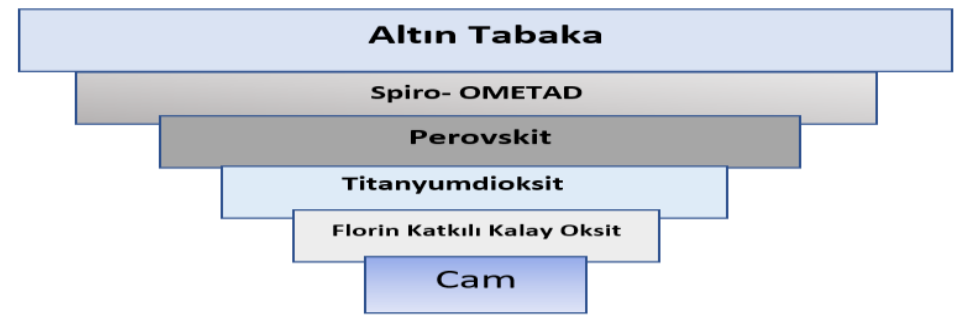

Şekil 2. Perovskit güneş hücrelerinin katmanlı yapısı [34]. 
Perovskit katmanı spin kaplama, iki adımlı daldırarak kaplama, termal buharlaştırma yöntemi gibi yöntemlerle veya bu yöntemlerin kombinasyonları ile üretilebilmektedir [38-43]. Spin kaplama tekniği ucuz, kolay ve çözücü bağımlı ve birçok adımlı olarak kullanılan bir yöntemdir. Bu teknikte, önce taban malzeme spin kaplama yüzeyine sabitlenir ve çözücü malzeme damlatılır. Daha sonra kaplanmak istenen solüsyon spin kaplama cihazının rotasyonel dönme hareketinden dolayı homojen olarak yüzeye yayılır ve merkezkaç kuvveti sayesinde fazlalık malzeme ayrıştırılır. Bu teknikte, solüsyon ve çözücüye bağlı olarak taban malzeme seçimi, taban malzeme sıcaklığının belirlenmesi ve spin kaplama cihazının hızını belirlenmesi çok önemlidir [41]. Termal buharlaştırma yöntemi, genel olarak vakum altında buharlaştırılmak istenilen malzemelerin, yüksek sıcaklıkta buharlaştırılarak taban malzeme üzerine büyütülmesi ilkesine dayanır [42]. İki adımlı daldırarak kaplama yönteminin birinci aşamasında, metal halide filmi, spin kaplama ya da termal buharlaştırma yöntemi ile oluşturulur. İkinci adımda ise ilk aşamada elde edilen malzeme, organik katyonlar içeren solüsyona daldırılır. Bu iki aşama sonucunda da perovskit yapı oluşur [43]. Sprey piroliz yöntemi ile de perovskit katmanı üretilebilmektedir. Bu yöntemin vakum ortamına ihtiyaç duymaması, yüksek sıcaklık gerektirmemesi ve geniş alanda kaplama için elverişli olması gibi avantajları bulunmaktadır. Bu alanda geliştirilen ultrasonik sprey piroliz tekniği ile yaklaşık \%80 oranında malzeme tasarrufu sağlanmaktadır [44]. Perovskit güneş pilleri, düzlemsel veya mezoyapılı mimaride yüksek verimli olarak üretilebilmektedir. $\mathrm{Bu}$ güneş pillerinin verim değeri, kullanılan halojen türleri ve oranları, katman üretim metotları, katmanın kristal boyutları gibi etkenlere bağlı olarak değişmektedir [45]. Stranks ve ark. [46] çalışmalarında, $\mathrm{CH}_{3} \mathrm{NH}_{3} \mathrm{PbI}_{3}$ ve $\mathrm{CH}_{3} \mathrm{NH}_{3} \mathrm{PbI}_{3-\mathrm{x}} \mathrm{Cl}_{\mathrm{x}}$ perovskit yapılarını elektron - boşluk difüzyon mesafeleri açısından incelemişlerdir. Bu elektron-boşluk difüzyon mesafelerini $\mathrm{CH}_{3} \mathrm{NH}_{3} \mathrm{PbI}_{3}$ için 100 $\mathrm{nm}$ ve $\mathrm{CH}_{3} \mathrm{NH}_{3} \mathrm{PbI}_{3-\mathrm{x}} \mathrm{Cl}_{\mathrm{x}}$ için $1 \mu \mathrm{m}$ olarak tespit etmişlerdir. Edri ve ark. [47] çalışmalarında, klorlu yapıdaki yüksek difüzyon mesafesinin düzlemsel ve mezo-süper yapıda yüksek performans sağladığını belirtmişlerdir. Ayrıca $\mathrm{CH}_{3} \mathrm{NH}_{3} \mathrm{PbI}_{3}$ yapısının elektron difüzyonunun mesafesini arttırabilmek için $\mathrm{TiO}_{2}$ katman yapısının kullanılması gerektiğini belirtmişlerdir. Shi ve ark. [48] çalışmalarında, düzlemsel ve mezoyapılı mimaride $\mathrm{CH}_{3} \mathrm{NH}_{3} \mathrm{PbI}_{3}$ ve $\mathrm{CH}_{3} \mathrm{NH}_{3} \mathrm{PbI}_{3-\mathrm{x}} \mathrm{Cl}_{\mathrm{x}}$ yapıların kullanarak perovskit güneş hücresi üretmişlerdir. $\mathrm{Bu}$ güneş hücrelerinin en yüksek verim değerini, düzlemsel mimaride $\mathrm{CH}_{3} \mathrm{NH}_{3} \mathrm{PbI}_{3-\mathrm{x}} \mathrm{Cl}_{\mathrm{x}}$ yapısı için \%12,67 ve $\mathrm{CH}_{3} \mathrm{NH}_{3} \mathrm{PbI}_{3}$ yapıs1 için ise \%14,05 olarak tespit etmişlerdir. Listorti ve ark. [49] çalışmalarında, mezoyapılı hücrelerde elde edilen $\mathrm{CH}_{3} \mathrm{NH}_{3} \mathrm{PbI}_{3-\mathrm{x}} \mathrm{Cl}_{\mathrm{x}}$ perovskit kristal boyutunun düzlemsel yapılara göre daha küçük olduğunu belirtmişlerdir.

\section{PEROVSKIT MALZEMELERIN YAPISI VE ÖZELLIKLERI}

Perovskit minerali, 1939 yılında Gustov tarafindan bulunmuştur ama Rus mineralog Kont Lev Alekseevich Perovskite, bu alandaki araştırmaları daha ileriye taşımıştır. Bundan dolayı bu mineraller perovskit olarak adlandırılmıştır [40]. Bakır oksit perovskit yapıların yüksek sıcaklıklarda ve süper iletken malzemelerde kullanılmasından sonra bu alanda yapılan araştırmalar artmıştır [50]. Bu alanda en çok incelenen perovskitler, ferroelektrik ve süper elektriksel iletkenlik özelliklerinden dolay1 oksitlerdir. Perovskit malzemelere olan ilgi, katmanlı organometal halojenür perovskitlerin artan boyutsallıkla yarı iletken-metale geçiş özelliklerinin tespit edilmesi ile artmıştır [43]. Mitzi ve ark. [51] çalışmalarında, organik-inorganik perovskitlerin optoelektronik özellikleri hakkında araştırma yapmışlardır ve bu malzemelerin güçlü eksiton özellikleri sergilediğini belirtmiş̧lerdir. Bu perovskit malzemeler arasında, yüksek simetri özelliğine sahip olan kübik perovskitler, güneş pillerinin performansında belirleyici bir rol oynamaktadır. Tablo 1'de bazı perovskit materyallerin faz geçiş sıcaklıkları görülmektedir [52,53]. 
Tablo 1. Bazı perovskitlerin kübik faz geçişsıcaklıkları [52,53].

\begin{tabular}{|cc|}
\hline Malzemeler & Sicaklık \\
\hline $\mathrm{CH}_{3} \mathrm{NH}_{3} \mathrm{PbCl}_{3}$ & $\sim 179$ \\
\hline $\mathrm{CH}_{3} \mathrm{NH}_{3} \mathrm{PbBr}_{3}$ & $\sim 237$ \\
\hline $\mathrm{CH}_{3} \mathrm{NH}_{3} \mathrm{PbI}_{3}$ & $\sim 327$ \\
\hline $\mathrm{HC}_{3}\left(\mathrm{NH}_{2}\right)_{2} \mathrm{PbI}_{3}$ & $\sim 360$ \\
\hline $\mathrm{CsPbBr}_{3}$ & $\sim 403$ \\
\hline $\mathrm{CsPbI}_{3}$ & $\sim 589$ \\
\hline
\end{tabular}

Perovskit malzemeler, mükemmel fotovoltaik performansları ve düşük maliyetli hammaddeleri sayesinde araştırmacılar arasında büyük ilgi görmektedir [54]. Perovskit malzemesi, $\mathrm{ABX}_{3}$ tipi moleküler yapıya sahip kalsiyum titanat $\left(\mathrm{CaTiO}_{3}\right)$ bileşiğinden elde edilmektedir. Perovskit malzemeler, yüksek elektron hareketliliği, yüksek taşıyıcı difüzyon uzunluğu, yüksek absorpsiyon katsayısı, optimum bant aralığı, düşük yüzey rekombinasyon hızı, ayarlanabilir bant aralığı, yüksek taşıyıcı ömrü, benzersiz optik, termal ve elektromanyetik özelliklere sahiptir [54-56]. Berhe ve ark. [57] çalışmalarında belirttikleri gibi perovskitlerin $\mathrm{ABX}_{3}$ formülasyonu 'Şekil 3'te görülmektedir. $\mathrm{Bu}$ $\mathrm{ABX}_{3}$ formülünde, A yerine Metil Amonyum $\left(\mathrm{CH}_{3} \mathrm{NH}_{3}\right)$, B yerine Kurşun $(\mathrm{Pb})$ ve $\mathrm{X}$ yerine $\mathrm{Klor}(\mathrm{Cl})$, Brom (Br) ya da İyot (I) kullanılmıştır. Yapıda kullanılan malzemelere kimyasal açıdan bakıldığında, geniş bir organik katyon metilamonyum $\left(\mathrm{CH}_{3} \mathrm{NH}_{3}\right)$, dar bir katyon kurşun $(\mathrm{Pb})$ ile halojen anyon olarak Klor (Cl), Brom (Br) ya da Iyot (I) kullanıldığı anlaşılmaktadır.
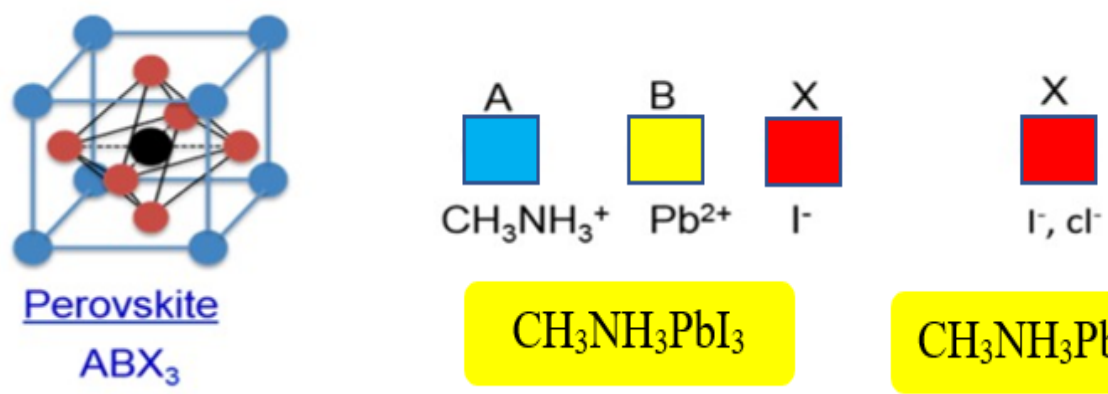

\section{$\mathrm{CH}_{3} \mathrm{NH}_{3} \mathrm{PbI}_{3-\mathrm{X}} \mathrm{Cl}$}

Şekil 3. Perovskit Malzemesinin $A B X_{3}$ Fornülasyonu [57].

Güneş pillerinde kullanılan perovskit malzemesi 'Wannier' tipi eksitona sahiptir. Bu nedenle, üretilen yük taşıyıcılar inorganik malzemede olduğu gibi davranır [58,59]. Roy ve ark. [25] çalışmalarında belirttikleri gibi organik-inorganik perovskit malzemelerin özellikleri 'Tablo 2'de görülmektedir. $\mathrm{Bu}$ özellikler, üretim sırasında kurucu parçacıkların şekli ve boyutu kontrol edilerek ayarlanabilir.

Tablo 2. Perovskit malzemelerin özellikleri [25].

\begin{tabular}{|c|c|}
\hline ÖZELLÍKLER & DEĞER ARALIĞI \\
\hline Bant aralığ 1 & $1.5-2.5 \mathrm{Ev}$ \\
\hline Soğurma katsayısı & $10^{5} \mathrm{~cm}^{-1}$ \\
\hline Eksiton bağlama enerjisi & 10 meV'den düşük \\
\hline Kristalizasyon enerji bariyeri & $56.6-97.3 \mathrm{kj} \mathrm{mol}^{-1}$ \\
\hline Fotoluminesans kuantum verimi & $\% 70$ \\
\hline Yüksek taşıyıcı ömrü & 300 nm’den büyük \\
\hline Bağıl (elektriksel) geçirgenlik & 3 \\
\hline Taşıyıcı (elektron) hareketliliği & $800 \mathrm{~cm}^{2} / \mathrm{Vs}$ \\
\hline Eksiton & Wannier tip \\
\hline Trap-state yoğunluğu & $\begin{array}{c}10^{10} \mathrm{~cm}^{3} \text { ( Tekli kristal) } \\
10^{15}-10^{17} \mathrm{~cm}^{3} \text { (Çoklu Kristal) }\end{array}$ \\
\hline
\end{tabular}




\section{PEROVSKITT GÜNES PILLERINDE KARARSIZLIK PROBLEMI}

Perovskit güneş pilleri, mükemmel potansiyele sahip olmalarına rağmen, normal çalışma koşulları altında kararsızlık göstermektedirler. Bu kararsızlık problemlerinden dolayı bu güneş pillerinin ticarileştirme aşamalarında kısıtlamalar meydana gelmektedir [57,60]. Perovskit güneş hücrelerindeki kararsızlık problemleri, su buharı, oksijen, elektriksel alan, 1şık ve sıcaklık gibi faktörlerden kaynaklanmaktadır $[38,42]$. Im ve ark. [27] çalışmalarında, perovskit güneş pillerinin üretiminden 10 dakika sonra bu güneş pillerinde $\% 80$ oranında bozulmaların meydana geldiğini belirtmişlerdir. Noh ve ark. [61] çalışmalarında, Spiro-OMeTAD tabanlı perovskit güneş hücreleri üreterek, bu güneş hücrelerinin kararlılık durumlarının 500 saate kadar çıktığını belirtmişlerdir. Lejitens ve ark. [62] çalışmalarında, $\mathrm{Al}_{2} \mathrm{O}_{3}$ tabanlı perovskit güneş hücrelerinin 1000 saat kararlılık durumuna ulaşıldığ1 rapor etmiş̧lerdir. Mei ve ark. [63] kararsızlık mekanizmasının çözümüne yönelik çalışma yapmışlardır. $\mathrm{Bu}$ çalışmada $\mathrm{TiO}_{2}$ tabakasının üzerine $\mathrm{ZrO}_{2}$ tabakasını büyütülmüştür ve elde edilen yapının üstüne ise kapsülasyon olarak gözenekli karbon ince film büyütülmüştür. $\mathrm{Bu}$ üç tabakalı yöntem sayesinde güneş 1şığında 1008 saat kararlı perovskit güneş hücresi üretilebilmiştir. Salado ve ark. [64] çalışmalarında, suyun perovskit güneş hücreleri üzerindeki etkisini incelemişlerdir. Perovskit güneş hücrelerinin 1-5 saat aralığında su ile temas etmesinden kaynaklanan bozulmalar tespit etmişlerdir. Jørgensen ve ark. [65] ise çalışmalarında, 1şık faktörünün de perovskit güneş pillerinde bozulmalara yol açtığını belirtmişlerdir.

\section{A. NEM VE OKSİJEN}

Belirli bir limitin üzerindeki oksijen ve nem, güneş hücresinin içerisinde oksidasyona sebep olmaktadır. Bu durumun sonucu olarak ortaya çıkan bozulma, perovskit güneş hücrelerinin dengesini bozar. Perovskit malzemenin bozulma problemi, nemin katalizör olarak etki ettiği bir kimyasal işlemdir [66-68]. Perovskit güneş pillerinin düşük bir nem seviyesinde ( $<\% 1$ atmosferde) olmalıdır [69]. Birçok çalışmada oksijenin, karanlıkta ve kuru atmosferde perovskit malzemenin kararlılığına etki etmediği belirtilmektedir [70,71]. Suarez ve ark. [72] çalışmalarında, polar çözücülerin perovskit yapılarında bozunmaya sebep oldukları belirtmişlerdir. Genelde boşluk transfer malzemesi olarak kullanılan Spiro-OMeTAD malzemesi su ortamında kararsızdır. Christians ve ark. [73] soğurucu tabakada bulunan suyun, kristal yapıyı etkilediğini ve buna bağlı olarak da perovskit soğurma spektrumunda taban ve uyarılmış durumlarda belirgin değişiklikler oluşturduğunu belirtmişlerdir. Yang ve ark. [74] çalışmalarında, bozunma etkisinin havadaki nem oranı ile doğru orantılı olduğunu vurgulamaktadırlar. Bu çalışmada onlarca gün $\% 50$ nem atmosferinde bozulmadan duran malzemenin, 3 gün \%80 nem atmosferinde beklemesi ile malzeme üzerinde belirgin oranda bozunmaların olduğu görülmüştür. Frost ve ark. [75] çalışmalarında, su molekülünün üretim esnasında birçok farklı kademede etkili olarak bozunmaya sebep olacağını belirmişlerdir ve perovskit güneş hücresinde suyun oluşturduğu bozunma döngüsü 'Şekil 4'te de görüldüğü gibi belirtmiş̧lerdir.

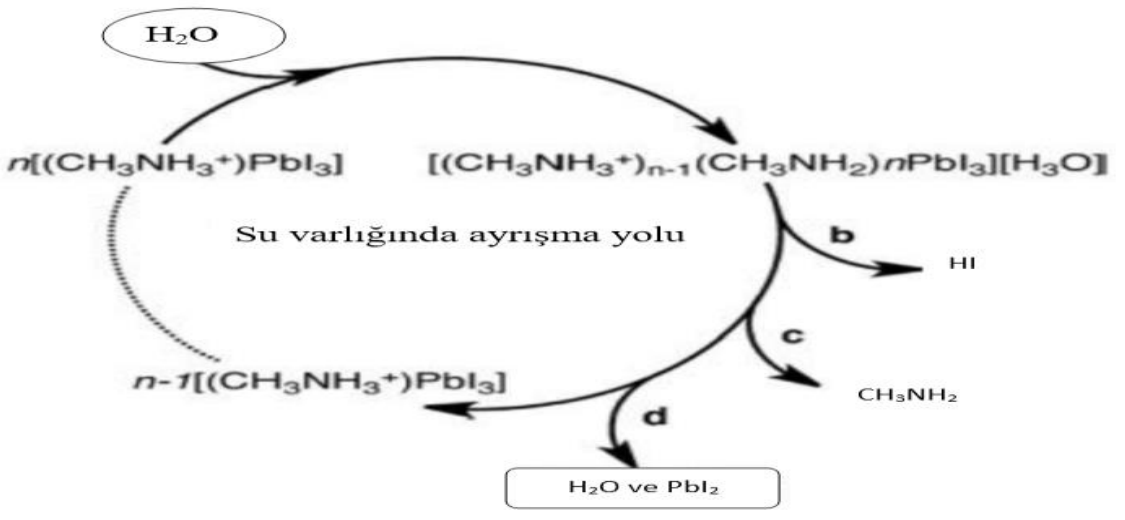

Şekil 4. Perovskit güneş hücresinde suyun oluşturduğu bozunma döngüsü [75]. 


\section{B. IŞIK}

Perovskit güneş hücrelerine etki eden UV 1şık, bu güneş hücrelerinde bozunmalara yol açmaktadır [76]. Leijtens ve ark. [62] perovskit güneş hücrelerinde ultraviyole 1ş1ktan kaynaklı bozunma probleminin temelinde $\mathrm{TiO}_{2}$ tabakası olduğunu belirtmişlerdir. Bu çalışmada UV kapsülasyonu olan ve UV kapsülasyonu olmayan iki farklı perovskit hücre 5 saat boyunca 1 güneş 1şı̆̆ şiddetinde 1şığa maruz bırakılmıştır. Bunun sonucunda isse UV kapsülasyonu olan hücrenin çok daha hızlı bir şekilde bozunma eğilimi gösterdiği görülmüştür. Birçok çalışmada belirtildiği gibi perovskit güneş hücrelerinde UV 1şıktan kaynaklı olarak oluşan bozunmanın sebebi $\mathrm{TiO}_{2}$ tabasında oluşan yüzey kimyası olarak nitelendirilmektedir [77,78]. Perovskitin bu tür bozunması, kimyasal bileşenleri ve karşlık gelen kristal yapıları ile güçlü bir şekilde ilişkilidir [79]. Nie ve ark. [80] çalışmalarında, cihazların karanlıkta 1 dakika bekletilerek tamamen iyileştiğini belirtmişlerdir. Yapılan teorik araştırmalara göre ve deneysel sonuçlara dayanarak, 1şıkla aktifleşen meta kararlı durumların sayısının artmasının, toplu filmde foto akımın bozulmasına yol açan yüklü alana neden olduğu sonucuna varıldı. $\mathrm{Bu}$ çalışmada cihaz karanlıkta dinlendirildiğinde, 1şıkla etkinleşen tuzak durumları kaybolduğu ve foto akımın orijinal sabit durum değerine geldiği tespit edilmiştir. Gözlenen bu hızlı kendi kendini iyileştirme veya stabilizasyon, foto stabilize perovskit güneş pillerinin gerçekleştirilmesi için sağlam bir temel oluşturmaktadır.

\section{SICAKLIK PROBLEMI}

Su ve ark. [81] çalışmalarında, $75^{\circ} \mathrm{C}$ ve $100^{\circ} \mathrm{C}$ 'de elde edilen XRD spektrumlarındaki pikleri incelediklerinde oluşturulmaya çalışılan $\mathrm{CH}_{3} \mathrm{NH}_{3} \mathrm{PbI}_{3-\mathrm{x}} \mathrm{Cl}_{\mathrm{x}}$ perovskit kristal yapısına ek olarak istenmeyen farklı yapıların da oluştuğunu gözlemlemişlerdir. Ayrıca, $125^{\circ} \mathrm{C}$ alttaş sıcaklığında üretilmiş yapılarda ise yapının tamamen $\mathrm{CH}_{3} \mathrm{NH}_{3} \mathrm{PbI}_{3-\mathrm{x}} \mathrm{Cl}_{\mathrm{x}}$ perovskit kristal formunda olduğunu tespit etmişlerdir [27]. Kim ve ark. [82] çalışmalarında, perovskit kristal boyutlarındaki artışın hem güneş 1şı̆̆ının soğruluşunu hem de yüzey iletkenliğini artırdığını, rekombinasyonu baskıladığını ve oluşturulacak güneş pili verimini doğrudan etkilediğini belirtmişlerdir. Alttaş sıcaklığının perovskit yapıları üzerindeki etkisi, 'Şekil 5'te görülmektedir [19].

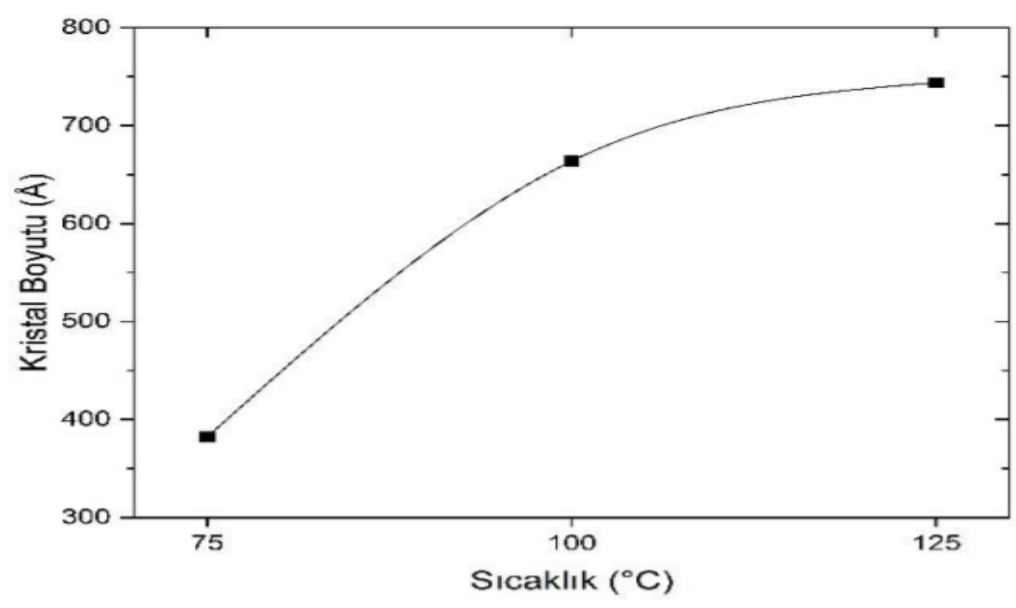

Şekil 5. Kristal boyutun slcakliğa bağll olarak değișimi [19].

Değişken sıcaklık değerlerinde perovskit malzemelerin tabakaları üzerinde farklı etkiler meydana gelmektedir. Belirli bir sıcaklık değerinin üstüne çıkıldığında perovskit malzemelerde bozunmalar meydana gelmektedir. Belirli sıcaklıkların altında ise malzeme içerisinde kristal yapı oluşmaktadır. Düşük sıcaklıkta $(\mathrm{T}<162.2 \mathrm{~K})$ kullanılan perovskitler, ortorombik durumdan orta sicaklıkta (162.2$327.4 \mathrm{~K}$ ) dörtgen faza geçer ve yüksek sıcaklıkta kullanılan perovskitler de ideal kübik fazdan ardışık faza geçerler. Ayrıca $327.4 \mathrm{~K}$ sıcaklığının üstüne çıkıldıkça, perovskitler uçucu $\mathrm{CH}_{3} \mathrm{NH}_{2}$ ve $\mathrm{HI}$ bileşiklerine bölünürler [83,84]. Misra ve ark. [85] çalışmalarında, 1şık enerjisi kaynaklı gerçekleşen ayrışmanın sıcaklıkla hızlandırılabilir olduğunu, yani güneş ışığından gelen 1şık enerjisi ve sıcaklık etkisinin perovskit güneş hücrelerinin bozulmasına neden olduğunu belirtmişlerdir. Bi ve ark. [86] ise 
çalışmalarında, iki adımlı perovskit güneş hücreleri üretim süreçlerinde $\mathrm{PbI}_{2}$ ve $\mathrm{MAI}$ büyütme safhalarında 1sıl tavlama sıcaklığının filmin kalitesini etkilediğini belirtmişlerdir.

\section{SONUC}

$\mathrm{Bu}$ çalışmada, güneş pillerinin özellikleri, üretimi ve verimleri üzerine araştırma yapılmıştır. Günümüzde kullanılan bakır indiyum galyum selenid, kristal silikon ve kadmiyum tellür gibi güneş pillerinin enerji dönüşüm süreleri yüksektir. Son yıllarda büyük gelişme gösteren perovskit güneş pillerinin ise enerji dönüşüm süreleri oldukça düşüktür. Kafle ve ark. [11] çalışmalarında, perovskit güneş pillerinin, güneş enerjisini elektrik enerjisine dönüştüren çevre dostu bir yöntem olduğunu belirtmişlerdir. Jena ve ark. [12] çalışmalarında, perovskit güneş pilleri teknolojisinde büyük ilerlemeler kaydedildiğini belirtmişlerdir. $\mathrm{Bu}$ güneş pillerindeki verim oranının artması, ticarileştirmeye yönelik maliyet avantajlarını artıracaktır [14]. Li ve ark. [22] çalışmalarında, 2020 yılında perovskit güneş pillerinin \%25,2 güç dönüştürme verimlilik değerine ulaştığını belirtmişlerdir. Perovskit güneş pillerinin emilim katsayıları oldukça yüksektir. Bu güneş pillerin işlenebilmeleri için yüksek sıcaklığa gerek yoktur ve bu güneş pillerinin bant aralıkları ayarlanabilmektedir. Bu güneş pillerinin yüksek potansiyeli olmasına rağmen üretildikten sonra su buharı, oksijen, elektriksel alan, 1şık ve sıcaklık gibi faktörlerden kaynaklanan kararsızlık problemleri meydana gelmektedir. Perovskit teknolojisi, ticarileşme eğilimi gösterdikçe, bu güneş pillerindeki kararlılık sorunları dikkat çekecektir ve ortalama ömrü 25 yıldan fazla olan perovskit güneş pillerinin geliştirilmesi odak noktası olacaktır.

\section{V.KAYNAKLAR}

[1] T. Jia, Y. Dai, ve R. Wang, "Refining energy sources in winemaking industry by using solar energy as alternatives for fosil fuels: A review and perspective," Renewable and Sustainable Energy Reviews, vol. 88, pp.278-296, 2018.

[2] A. C. Marques, J. A. Fuinhas, ve D. A. Pereira, "Have fossil fuels been substituted by renewables? An empirical assessment for 10 European countries," Energy Policy, vol.116, pp.257$265,2018$.

[3] A. Çiğan, ve R. Yamaçl1, "Doğal enerji, sürdürülebilir kalkınma ve mimarlık politikalar1,” Düzce Üniversitesi Bilim ve Teknoloji Dergisi, c.8, s.1, ss.554-571, 2020.

[4] Z. Ö. Özdemir ve K. Günduğar, "Birinci, ikinci nesil biyoetanol üretimi ve Türkiye'deki biyoetanol üretiminin durumu \& kapasitesi," Düzce Üniversitesi Bilim ve Teknoloji Dergisi, c.7, s.3, ss.1290-1298, 2019

[5] Z. Zhang, Z. Li, L. Meng, S.Y. Lien, ve P. Gao, "Perovskite based tandem solar cells: get the most out of the Sun," Advanced Functional Materials, c. 30, s. 38, ss. 2001904, 2020.

[6] A. Khare, "A critical review on the efficiency improvement of upconversion assisted solar cells," Journal of Alloys and Compounds, vol. 82, pp.153214, 2020.

[7] S. B. Darling, F. You, T. Veselka, ve A. Velosa, "Assumptions and the levelized cost of energy for photovoltaics," Energy \& Environmental Science, vol. 4, no. 9, pp.3133-3139, 2011.

[8] K. Boran, "Sezgisel Bulanık TOPSIS Yöntemi Kullanarak Türkiye'nin Yenilenebilir Enerji Kaynaklarının Değerlendirilmesi," Politeknik Dergisi, vol.20, no.3, pp.629-637, 2017. 
[9] M. Bilgin ve K. Çelebi, "Autonomous photovoltaic solar cell using tracking system design and 1mplementation," Honorary Editor, c. 9, s. 2, ss. 1669-1676, 2019.

[10] M.O. Karaağaç, H. Oğul ve S. Bardak, "Kanatlı hayvan çiftliği için güneş enerji sisteminin tasarımı ve maliyet hesab1," Düzce Üniversitesi Bilim ve Teknoloji Dergisi, c.8, s.1, ss.711-722, 2020.

[11] B.P. Kafle, B.R. Pokhrel, R. Gyawali, A. Kafle, T. M. Shrestha, R. Shrestha ve R. M. Adhikari, "Absorbance of natural and synthetic dyes: Prospect of application as sensitizers in dye sensitized solar cell," Advances in Applied Science Research, c. 5, s. 1, ss. 8-12, 2014.

[12] A. K. Jena, A. Kulkarni, ve T. Miyasaka, "Halide perovskite photovoltaics: background, status, and future prospects," Chemical Reviews, c.119, s. 5, ss. 3036-3103, 2019.

[13] M. Ç. Çadırcı, V. Y. Oğuz ve S. ertan, "Numerical Analysis and Optimization of CH3NH3PbI3-xCIx Based Perovskite Solar Cells," Düzce Üniversitesi Bilim ve Teknoloji Dergisi, c.9, s.1, ss.28-39, 2021.

[14] Y. Rong, Y. Hu, A. Mei, H. Tan, M. I. Saidaminov, S. L. Seok, ve H. Han, "Challenges for commercializing perovskite solar cells," Science, c. 361, ss. 6408, 2018.

[15] W. Ke, D. Zhao, C. R. Grice, A. J. Cimaroli, G. Fang ve Y. Yan, "Efficient fully-vacuumprocessed perovskite solar cells using copper phthalocyanine as hole selective layers," Journal of Materials Chemistry A, c. 3, s. 47, ss. 23888-23894, 2015.

[16] Grätzel, M. (2014). The light and shade of perovskite solar cells. Nature materials, 13(9), 838842.

[17] H. S. Kim, C. R. Lee, J. H. Im, K. B. Lee, T. Moehl, A. Marchioro, ve M. Grätzel, "Lead iodide perovskite sensitized all-solid-state submicron thin film mesoscopic solar cell with efficiency exceeding 9\%," Scientific Reports, c. 2, s.1, ss. 1-7, 2012.

[18] Z. Wu, M. Jiang, Z. Liu, A. Jamshaid, L.K. Ono, ve Y.Qi, "Highly efficient perovskite solar cells enabled by multiple ligand passivation." Advanced Energy Materials, c.10, s.10, ss.1903696, 2020 .

[19] S. Akyürekli, M. Kaleli, M. Koç ve D. A. Aldemir, "Ultrasonik sprey piroliz yöntemi ile üretilen güneş soğurucu $\mathrm{CH} 3 \mathrm{NH} 3 \mathrm{PbI} 3-\mathrm{xClx}$ perovskit yapısının optik, morfolojik ve yapısal özelliklerinin incelenmesi," Süleyman Demirel Üniversitesi Fen Edebiyat Fakültesi Fen Dergisi, c. 15, s. 2, ss. 253-263, 2020.

[20] T. J. Jacobsson, J. P. Correa-Baena, M. Pazoki, M. Saliba, K. Schenk, M. Grätzel ve A. Hagfeldt, "Exploration of the compositional space for mixed lead halogen perovskites for high efficiency solar cells," Energy \& Environmental Science, c. 9, s. 5, ss. 1706-1724, 2016.

[21] W. S. Yang, B.W. Park, E. H. Jung, N. J. Jeon, Y. C. Kim, D. U. Lee ve S. I. Seok, "Iodide management in formamidinium-lead-halide-based perovskite layers for efficient solar cells," Science, c. 356, s. 6345, ss. 1376-1379, 2017.

[22] H. Li, C. Cui, X. Xu, S. Bian, C. Ngaojampa, P. Ruankham, ve A.P. Jaroenjittchai, “A review of characterization of perovskite film in solar cells by spectroscopic ellipsometry," Solar Energy, c. 212, ss. 48-61, 2020.

[23] Srivastava, S., Singh, S., \& Singh, V. K. (2021). Bulk and interface defects analysis of n-CdS/p-Si heterojunction solar cell. Optical Materials, 111, 110687. 
[24] Shin, D. Y., Lim, J. R., Shin, W. G., Lee, C. G., \& Kang, G. H. (2021). Layup-only modulization for low-stress fabrication of a silicon solar module with $100 \mu \mathrm{m}$ thin silicon solar cells. Solar Energy Materials and Solar Cells, 221, 110903.

[25] P. Roy, N. K. Sinha, S. Tiwari ve A. Khare, "A review on perovskite solar cells: Evolution of architecture, fabrication techniques, commercialization issues and status," Solar Energy, c. 198, ss. 665-688, 2020.

[26] A. Kojima, K. Teshima, Y. Shirai, \& T. Miyasaka, "Organometal halide perovskites as visible-light sensitizers for photovoltaic cells," Journal of the American Chemical Society, vol 31, no.17, ss.6050-6051,2009.

[27] J. H. Im, C. R. Lee, J. W. Lee, S. W. Park ve N. G. Park, " $6.5 \%$ efficient perovskite quantumdot-sensitized solar cell," Nanoscale, c. 3, s. 10, ss. 4088-4093, 2011.

[28] M. A. Green, A. Ho-Baillie ve H. J. Snaith, "The emergence of perovskite solar cells," Nature Photonics, c. 8, s. 7, ss. 506-514, 2014.

[29] S. Yang, W. Fu, Z. Zhang, H. Chen, ve C. Z. Li, "Recent advances in perovskite solar cells: efficiency, stability and lead-free perovskite," Journal of Materials Chemistry, c. 5, s. 23, ss. $11462-$ $11482,2017$.

[30] S. Sharma, K. K. Jain ve A. Sharma, "Solar cells: in research and applications-a review," Materials Sciences and Applications, c. 6, s. 12, ss. 1145, 2015.

[31] T. B. Song, Q. Chen, H. Zhou, C. Jiang, H. H. Wang, Y. M. Yang ve Y. Yang, "Perovskite solar cells: film formation and properties," Journal of Materials Chemistry A, c. 3, s. 17, ss. 90329050, 2015.

[32] N. L. Panwar, S. C. Kaushik \& S. Kothari, "Role of renewable energy sources in environmental protection: A review," Renewable And Sustainable Energy Reviews, c. 15, s. 3, ss. 1513-1524, 2011.

[33] Y. Zhang, N.G. Park, "A thin film $(<200 \mathrm{~nm})$ perovskite solar cell with $18 \%$ efficiency." Journal of Materials Chemistry A, c.8, s.34, ss.17420-17428,2020.

[34] Q. Wali, F. J. Iftikhar, M. E. Khan, A. Ullah, Y. Iqbal ve R. Jose, "Advances in stability of perovskite solar cells," Organic Electronics, c. 78, ss. 105590, 2020.

[35] M. Abd Mutalib, F. Aziz, A. F. Ismail, W. N. W. Salleh, N. Yusof, J. Jaafar, ve N. A. Ludin, "Towards high performance perovskite solar cells: A review of morphological control and HTM development," Applied Materials Today, c.13, ss.69-82, 2018.

[36] S. Yurtdaş, C. A. N. Mustafa, M. Karaman ve C. Tozlu, "Polimerik güneş hücrelerinde ag nanopartikül katkılı $\mathrm{TiO}_{2}$ tampon tabakasının kendiliğinden organize olan tek tabaka moleküller (SAM) ile modifiye edilmesi," Düzce Üniversitesi Bilim ve Teknoloji Dergisi, c.8, s.1, ss.1058-1071, 2020.

[37] B. K1lıç, "Yeni nesil güneş hücrelerinde hibrit nano-yarilletkenlerin sentezlenerek optoelektronik özelliklerinin incelenmesi," Düzce Üniversitesi Bilim ve Teknoloji Dergisi, c.9, s.1, ss.51-59, 2021.

[38] Y. Ma, S. Wang, L. Zheng, Z. Lu, D. Zhang, Z. Bian ve L. Xiao. "Recent research developments of perovskite solar cells," Chinese Journal of Chemistry, c. 32, s. 10, ss. 957-963, 2014. 
[39] Q. Chen, H. Zhou, Z. Hong, S. Luo, H. S. Duan, H. H. Wang ve Y. Yang, "Planar heterojunction perovskite solar cells via vapor-assisted solution process," Journal of the American Chemical Society, c. 136, s. 2, ss. 622-625, 2014.

[40] S. Razza, F. Di Giacomo, F. Matteocci, L. Cin Ó, A. L. Palma, S. Casaluc ve A. Di Carlo, "Perovskite solar cells and large area modules $\left(100\right.$ ácm $\left.{ }^{2}\right)$ based on an air flow-assisted $\mathrm{PbI}_{2}$ blade coating deposition process," Journal of Power Sources, c. 277, ss. 286-291, 2015.

[41] G. Yılmaz ve Ç. Özkök, "Perovskit Güneş Hücreleri ve Kararsızlık Problemleri," Mehmet Akif Ersoy Üniversitesi Fen Bilimleri Enstitüsü Dergisi, c. 9, s. 1, ss. 297-304, 2019.

[42] M. Liu, M. B. Johnston ve H. J. Snaith, "Efficient planar heterojunction perovskite solar cells by vapour deposition," Nature, c. 501, s.7467, ss. 395-398, 2013.

[43] D. B. Mitzi, C. A. Feild, W. T. A. Harrison ve A.M. Guloy, "Conducting tin halides with a layered organic-based perovskite structure," Nature, c. 369, s. 6480, ss. 467-469, 1994.

[44] B. Dwi, "Comparison of $\mathrm{SnO} 2 / \mathrm{Si}-\mathrm{n}$ thin films deposited by pneumatic spray pyrolysis technique with that deposited by ultrasonic spray Pyrolysis Technique," Indonesian Journal of Materials Science, c. 43, ss. 241-245, 2008.

[45] J. Burschka, N. Pellet, S. J. Moon, R. Humphry-Baker, P. Gao, M. K. Nazeeruddin ve M. Grätzel, "Sequential deposition as a route to high-performance perovskite-sensitized solar cells," Nature, c. 499, s. 7458, ss. 316-319, 2013.

[46] S. D. Stranks, G. E. Eperon, G. Grancini, C. Menelaou, M. J. Alcocer, T. Leijtens ve H. J. Snaith, "Electron-hole diffusion lengths exceeding 1 micrometer in an organometal trihalide perovskite absorber," Science, c. 342, s. 6156, ss. 341-344, 2013.

[47] E. Edri, S. Kirmayer, A. Henning, S. Mukhopadhyay, K. Gartsman, Y. Rosenwaks ve D. Cahen, "Why lead methylammonium tri-iodide perovskite-based solar cells require a mesoporous electron transporting scaffold (but not necessarily a hole conductor)," Nano Letters, c. 14, s. 2, ss. 1000-1004, 2014.

[48] Y. Shi, Y. Xing, Y. Li, Q. Dong, K. Wang, Y. Du ve T. Ma, " $\mathrm{CH}_{3} \mathrm{NH}_{3} \mathrm{PbI}_{3}$ and $\mathrm{CH}_{3} \mathrm{NH}_{3} \mathrm{PbI}_{3-}$ ${ }_{\mathrm{x}} \mathrm{Cl}_{\mathrm{x}}$ in planar or mesoporous perovskite solar cells: comprehensive insight into the dependence of performance on architecture," The Journal of Physical Chemistry C, c. 119, s. 28, ss. 15868-15873, 2015.

[49] A. Listorti, E. J. Juarez-Perez, C. Frontera, V. Roiati, L. Garcia-Andrade, S. Colella ve I. Mora-Sero, "Effect of mesostructured layer upon crystalline properties and device performance on perovskite solar cells," The Journal Of Physical Chemistry Letters, c. 6, s. 9, ss. 1628-1637, 2015.

[50] J. G. Bednorz ve K. A. Müller, "Possible highT c superconductivity in the $\mathrm{Ba}-\mathrm{La}-\mathrm{Cu}-\mathrm{O}$ system," Zeitschrift für Physik B Condensed Matter, c. 64, s. 2, ss. 189-193, 1986.

[51] D. B. Mitzi, K. Chondroudis, ve C. R. Kagan, "Organic-inorganic electronics," IBM Journal Of Research And Development, c. 45, s.1, ss. 29-45, 2001.

[52] C. C. Stoumpos, C. D. Malliakas, ve M. G. Kanatzidis, "Semiconducting tin and lead iodide perovsk ites with organic cations: phase transitions, high mobilities, and near-infrared photoluminescent properties," Inorganic Chemistry, c. 52, s. 15, ss. 9019-9038, 2013. 
[53] S. Sharma, N. Weiden, ve A.Weiss, "Phase diagrams of quasibinary systems of the type: $\mathrm{ABX} 3-\mathrm{A}^{\prime} \mathrm{BX} 3 ; \mathrm{ABX}_{3}-\mathrm{AB}^{\prime} \mathrm{X}_{3}$, and $\mathrm{ABX}_{3}-\mathrm{ABX}^{\prime}{ }_{3} ; \mathrm{X}=$ halogen," Zeitschrift für Physikalische Chemie, c.175, s.1, ss. 63-80, 1992.

[54] D. Zhou, T. Zhou, Y. Tian, X. Zhu, ve Y. Tu, "Perovskite-based solar cells: materials, methods, and future perspectives," Journal of Nanomaterials, c. 2018, 2018.

[55] A. Miyata, A. Mitioglu, P. Plochocka, O. Portugall, J. T. W. Wang, S. D. Stranks, ve R. J. Nicholas, "Direct measurement of the exciton binding energy and effective masses for charge carriers in organic-inorganic tri-halide perovskites," Nature Physics, c. 11, s. 7, ss. 582-587, 2015.

[56] G. Xing, N. Mathews, S. Sun, S. S. Lim, Y. Lam, M. Grätzel, ve T. C. Sum, "Long-range balanced electron-and hole-transport lengths in organic-inorganic $\mathrm{CH}_{3} \mathrm{NH}_{3} \mathrm{PbI}_{3}$," Science, c. 342, s. 6156, ss. 344-347, 2013.

[57] T. A. Berhe, W. N. Su, C. H. Chen, C. J. Pan, J. H. Cheng, H. M. Chen, ve B. J. Hwang, "Organometal halide perovskite solar cells: degradation and stability," Energy \& Environmental Science, c. 9, s. 2, ss. 323-356, 2016.

[58] M. Hirasawa, T. Ishihara, T. Goto, K. Uchida, ve N. Miura, "Magnetoabsorption of the lowest exciton in perovskite-type compound (CH3NH3) $\mathrm{PbI}_{3}$," Physica B: Condensed Matter, c. 201, ss. 427430, 1994.

[59] T. Minemoto, ve M. Murata, "Device modeling of perovskite solar cells based on structural similarity with thin film inorganic semiconductor solar cells," Journal of Applied Physics, c. 116, s. 5, ss. 054505, 2014.

[60] D. Wang, M. Wright, N. K. Elumalai, ve A. Uddin, "Stability of perovskite solar cells," Solar Energy Materials and Solar Cells, c. 147, ss. 255-275, 2016.

[61] J. H. Noh, S. H. Im, J. H. Heo, T. N. Mandal ve S. I. Seok, "Chemical management for colorful, efficient, and stable inorganic-organic hybrid nanostructured solar cells," Nano Letters, c. 13, s. 4, ss. 1764-1769, 2013

[62] T. Leijtens, G. E. Eperon, S. Pathak, A. Abate, M. M. Lee ve H. J. Snaith, "Overcoming ultraviolet light instability of sensitized $\mathrm{TiO}_{2}$ with meso-superstructured organometal tri-halide perovskite solar cells," Nature Communications, c. 4, s. 1, ss. 1-8, 2013.

[63] A. Mei, X. Li, L. Liu, Z. Ku, T. Liu, Y. Rong, ve H. Han, "A hole-conductor-free, fully printable mesoscopic perovskite solar cell with high stability," Science, c. 345, s. 6194, ss. 295-298, 2014.

[64] M. Salado, L. Contreras-Bernal, L. Caliò, A. Todinova, C. López-Santos, S. Ahmad, J. A. Anta, "Impact of moisture on efficiency-determining electronic processes in perovskite solar cells," Journal of Materials Chemistry A, c. 5, s. 22, ss. 10917-10927, 2017.

[65] M. Jørgensen, K. Norrman, ve F. C. Krebs, "Stability/degradation of polymer solar cells," Solar Energy Materials And Solar Cells, c. 92, s. 7, ss. 686-714, 2008.

[66] G. Niu, X. Guo, ve L. Wang, "Review of recent progress in chemical stability of perovskite solar cells," Journal of Materials Chemistry A, c. 3, s. 17, ss. 8970-8980, 2015.

[67] H. S. Kim, S. H. Im, ve N. G. Park, "Organolead halide perovskite: new horizons in solar cell research,” The Journal of Physical Chemistry C, c. 118, s.11, ss. 5615-5625, 2014. 
[68] S. Bai, Z. Wu, X. Wu, Y. Jin, N. Zhao, Z. Chen ve B. Sun, "High-performance planar heterojunction perovskite solar cells: Preserving long charge carrier diffusion lengths and interfacial Engineering," Nano Research, c. 7, s. 12, ss. 1749-1758, 2014.

[69] W. Li, J. Li, L. Wang, G. Niu, R. Gao ve Y. Qiu, "Post modification of perovskite sensitized solar cells by aluminum oxide for enhanced performance," Journal of Materials Chemistry A, c. 1, s. 38, ss. 11735-11740, 2013.

[70] H. S. Kim, C. R. Lee, J. H. Im, K. B. Lee, T. Moehl, A. Marchioro ve N. G. Park, "Lead iodide perovskite sensitized all-solid-state submicron thin film mesoscopic solar cell with efficiency exceeding 9\%," Scientific Reports, c. 2, s.1, ss. 1-7, 2012.

[71] M. M. Lee, J. Teuscher, T. Miyasaka, T. N. Murakami ve H. J. Snaith, "Efficient hybrid solar cells based on meso-superstructured organometal halide perovskites," Science, c. 338, s. 6107, ss. 643647, 2012.

[72] B. Suarez, V. Gonzalez-Pedro, T.S. Ripolles, R. S. Sanchez, L. Otero ve I. Mora-Sero, "Recombination study of combined halides $(\mathrm{Cl}, \mathrm{Br}, \mathrm{I})$ perovskite solar cells," The Journal Of Physical Chemistry Letters, c. 5, s. 10, ss. 1628-1635, 2014.

[73] J. A. Christians, P. A. Miranda Herrera ve P. V. Kamat, "Transformation of the excited state and photovoltaic efficiency of $\mathrm{CH}_{3} \mathrm{NH}_{3} \mathrm{PbI}_{3}$ perovskite upon controlled exposure to humidified air," Journal of the American Chemical Society, c. 137, s. 4, ss. 1530-1538, 2015.

[74] J. Yang, B. D. Siempelkamp, D. Liu ve T. L. Kelly, "Investigation of $\mathrm{CH}_{3} \mathrm{NH}_{3} \mathrm{PbI}_{3}$ degradation rates and mechanisms in controlled humidity environments using in situ techniques," $A C S$ Nano, c. 9, s. 2, ss. 1955-1963, 2015.

[75] J. M. Frost, K. T. Butler, F. Brivio, C. H. Hendon, M. Van Schilfgaarde ve A. Walsh, "Atomistic origins of high-performance in hybrid halide perovskite solar cells," Nano Letters, c. 14, s. 5, ss. 2584-2590, 2014.

[76] A. Hinsch, J. M. Kroon, R. Kern, I, Uhlendorf, J. Holzbock, A. Meyer ve J. Ferber, "Long term stability of dye sensitised solar cells," Progress in Photovoltaics: Research and Applications, c. 9, s. 6, ss. 425-438, 2001.

[77] J. Bisquert, F. Fabregat-Santiago, I. Mora-Seró, G. Garcia-Belmonte, E. M. Barea, ve E. Palomares, "A review of recent results on electrochemical determination of the density of electronic states of nanostructured metal-oxide semiconductors and organic hole conductors," Inorganica Chimica Acta, c. 361, s. 3, ss. 684-698, 2008.

[78] K. Schwanitz, U. Weiler, R. Hunger, T. Mayer ve W. Jaegermann, "Synchrotron-induced photoelectron spectroscopy of the dye-sensitized nanocrystalline $\mathrm{TiO}_{2} /$ electrolyte interface: band gap states and their interaction with dye and solvent molecules," The Journal of Physical Chemistry C, c. 111, s. 2, ss. 849-854, 2007.

[79] Q. Fu, X. Tang, B. Huang, T. Hu, L. Tan, L. Chen ve Y. Chen, "Recent progress on the long term stability of perovskite solar cells," Advanced Science, c. 5, s. 5, ss. 1700387, 2018.

[80] W. Nie, J. C. Blancon, A. J. Neukirch, K. Appavoo, H. Tsai, M. Chhowalla, ve A. D. Mohite, "Light-activated photocurrent degradation and self-healing in perovskite solar cells," Nature Communications, c. 7, s. 1, ss. 1-9, 2016.

[81] J. Su, W. F. Wang, Y. Lei, L. Zhang, L. H. Xu, D. Wang ve Y. Bai, "On the growth of CH3NH3PbI3-xClx single crystal and characterization," Physica B: Condensed Matter, c. 537, ss. 7$11,2018$. 
[82] B. Kim, G. H. Moon, S. C. Park, J. Jang ve Y. S. Kang, "Effects of crystal size and surface coverage of perovskites on electron recombination in solar cells," Materials Letters, c. 242, ss. 191194, 2019.

[83] Z. Cheng ve J. Lin, "Layered organic-inorganic hybrid perovskites: structure, optical properties, film preparation, patterning and templating Engineering," CrystEngComm, c. 12, s. 10, ss. 2646-2662, 2010.

[84] A. Pisoni, J. Jacimovic, O. S. Barisic, M. Spina, R. Gaál, L. Forró ve E. Horváth, "Ultra-low thermal conductivity in organic-inorganic hybrid perovskite CH3NH3PbI3," The Journal Of Physical Chemistry Letters, c. 5, s. 14, ss. 2488-2492, 2014.

[85] R. K. Misra, S. Aharon, B. Li, D. Mogilyansky, I. Visoly-Fisher, L. Etgar ve E. A. Katz, "Temperature-and component-dependent degradation of perovskite photovoltaic materials under concentrated sunlight," The Journal Of Physical Chemistry Letters, c. 6, s. 3, ss. 326-330, 2015.

[86] C. Bi, Y. Shao, Y. Yuan, Z. Xiao, C. Wang, Y. Gao ve J. Huang, "Understanding the formation and evolution of interdiffusion grown organolead halide perovskite thin films by thermal annealing," Journal of Materials Chemistry A, c. 2, s. 43, ss. 18508-18514, 2014. 